\title{
Regeneration of Bovine Mammary Gland in Immunodeficient Mice by Transplantation of Bovine Mammary Epithelial Cells Mixed with Matrigel
}

\author{
Hyun Jung Park ${ }^{1}$, Won Young Lee ${ }^{2}$, Ha Yeon Jeong ${ }^{3}$, Hyuk Song ${ }^{1}$ \\ ${ }^{I}$ Department of Stem Cell and Regenerative Biology, College of Animal Biotechnology, Konkuk University, Seoul, \\ ${ }^{2}$ Department of Food Bioscience, Research Institute for Biomedical \& Health Science, \\ College of Biomedical \& Health Science, Konkuk University, Chungju, \\ ${ }^{3}$ Dairy Science Division, National Institute of Animal Science, RDA, Wanju, Korea
}

Background and Objectives: With the global demand for dairy protein for consumption growing annually, there has been increasing activity in the research field of dairy protein synthesis and production. From a manipulation perspective, it is more difficult to use live cattle for laboratory studies on the production of milk as well as of dairy protein such as casein, as compared with using laboratory animals like rodents. Therefore, we aimed to develop a mouse model of bovine mammary alveolar ducts for laboratory-scale studies. We studied the formation of the bovine mammary gland ductal structure by transplanting the MAC-T bovine alveolar cell line into mice.

Methods and Results: MAC-T cells $\left(1 \times 10^{7}\right)$ were suspended in Matrigel and injected into the dorsal tissue of 8-week-old male BALB/C nude mice. Histological analysis of tissue dissected from the MAC-T cell-transplanted mice after 6 weeks showed the typical morphology of the tubuloalveolar female gland, as well as glands made up of branching ducts that were surrounded by smooth muscle with small alveoli budding off the ducts. In addition, the epithelial markers CK14 and CK18 were expressed within the duct-like structure. Prolactin was detected in the duct interior in these CK14+ and $\mathrm{CK} 18+$ cells but not in the non-transplanted MAC-T cells.

Conclusions: These results showed that duct-like tissue had been successfully formed after 6 weeks of transplantation of the CK14+ and CK18 + MAC-T cells into mice dorsal tissue. This mouse model will be a useful tool for further research on the bovine mammary gland.

Keywords: Bovine mammary gland, MAC-T cell, BALB/C nude mice, CK14, CK18, Prolactin

Accepted for publication September 13, 2016, Published online November 30, 2016

Correspondence to Hyuk Song

Department of Stem Cell and Regenerative Biology, College of Animal Biotechnology, Konkuk University, 120 Neungdong-ro, Gwangjin-gu, Seoul 05029, Korea

Tel: +82-2-450-0562, Fax: +82-2-455-1044

E-mail: songh@konkuk.ac.kr

(a) This is an open-access article distributed under the terms of the Creative Commons Attribution Non-Commercial License (http://creativecommons.org/ licenses/by-nc/4.0/), which permits unrestricted non-commercial use, distribution, and reproduction in any medium, provided the original work is properly cited.

\section{Introduction}

The mammalian mammary gland is a complex organ, made up of various cell types that work together for milk synthesis. In females, the mammary gland has a ductal structure that supports formation of the alveolar structure during pregnancy, prior to the onset of lactogenesis $(1,2)$. The primary mammary duct invades the mammary fat pad at E17, and formation of a small, branched ductal tree begins at this time and develops its shape (3). A previous study had established a clonal cell line from primary bovine mammary alveolar cells (MAC-T) for the study of bo- 
vine milk production and synthesis (4). Prolactin was used to induce the MAC-T cell differentiation. The differentiated cells had important characteristics of increases in their beta-casein mRNA abundance as well as number and size of casein secretory vesicles, and the ability to secrete alpha-S- and beta-casein proteins (4). Dairy proteins have been reported to have favorable effects on oxidative stress and inflammation, as well as conveying human health advantages such as blood pressure, blood lipid, and glucose control $(5,6)$. Based on these positive effects of dairy protein, many researchers have attempted to investigate the mechanism of casein production for increasing its content in milk. For example, hormones such as somatotropin, growth hormone, retinoic acid, and prolactin have been shown to increase milk protein synthesis in mammary cell models $(7,8)$. However, the cell signaling mechanism that may be involved in mediating the effect of growth hormones on milk production in the mammary gland of lactating dairy cows is still unknown (9). Knowledge about such hormone-related mechanism would help to define a novel means of steroid receptor-mediated transcriptional repression of a physiologically important gene in mammary gland development and differentiation (10). The MAC-T cell line has the characteristics of uniform differentiation, immortality, and a population doubling time of approximately $17 \mathrm{~h}$ (4). These cells may be very useful for dairy protein synthesis studies, particularly of casein. Generally, farm animals such as cattle and horses are difficult to handle for experiments. The mouse, on the other hand, is the most commonly used mammalian research model for laboratory-scale experiments. Hence, it would be beneficial to develop a mouse model of bovine mammary alveolar ducts for laboratory scale-studies. Here, we aimed to generate the bovine mammary gland ductal structure from MAC-T cells transplanted into mice dorsal tissue.

\section{Materials and Methods}

\section{Animal and MACT cell transplantation}

The MAC-T bovine mammalian epithelial cell line was cultured in Dulbecco's modified Eagle's medium (DMEM; Gibco-BRL, Gaithersburg, DM, USA) containing $25 \mathrm{mM}$ glucose, supplemented with $10 \%$ fetal bovine serum (FBS; Welgene, Daejeon, South Korea), $100 \mathrm{U} / \mathrm{ml}$ penicillin and $100 \mu \mathrm{g} / \mathrm{ml}$ streptomycin (Gibco 15140-122). The cells were grown in a humidified $5 \% \mathrm{CO} 2$ atmosphere at $37^{\circ} \mathrm{C}$. Seven-week-old female BALB/C nude mice were purchase from Orient bio Inc. Seongnam, Korea) and animals were housed in an environmentally controlled room (temperature:
$23 \pm 2^{\circ} \mathrm{C}$, relative humidity: $50 \pm 10 \%$, programmed ventilation, and 12:12 h light-dark cycle) prior to experiment. All of the animal experiments were approved by the University of Konkuk Animal Care Use Committee. Ethics approval for this project was granted by the Institutional Animal Care and Use Committee (IACUC, KU16078). MAC-T cells (1X107) were suspended in BD Matrigel $^{\mathrm{TM}}$ diluted 1:1 (v/v) in Hank's Balanced Salt Solution (HBSS, Gibco). Cell suspension in Matrigel was injected into the 8 weeks male BALB/C nude mice dorsal using syringe for transplantation. After 6 weeks, small portion of the transplanted tissue was dissected from BALB/C nude mice and fixed in Bouin solution for immunostaining. For analyzing of bovine mammary gland protein expression, to perform a mammalian gland biopsy from fourteen month calf and fixed in Bouin solution.

\section{Immunocytochemistry}

The MAC-T cells were seeded in 6-well plate at a density of $1 \times 10^{5}$ cells/well and cell were fixed for $10 \mathrm{~min}$ with $4 \%$ paraformaldehyde, permeabilized for 10 miin with $0.2 \%$ Triton X-100, and then incubation for 1 hour with $3 \%$ BSA in PBS to block nonspecific antibody binding. Cells were incubated with a 1:200 dilution of anti-cytokeratin 18 (CK-18), anti-cytokeratin 14 (CK-14) or anti Prolactin for 1 hour. The cell were then rinsed with PBS and incubated with anti-mouse Alexa 568 and anti-rabbit Alexa 488 antibody (both 1:500; Invitrogen, Carlsbad, CA, USA) for 1 hour. Samples were rinsed in PBS for $15 \mathrm{~min}$ and incubated on DAPI for $10 \mathrm{~min}$.

\section{Immunohistochemistry}

Tissues were rinsed PBS, fixed in Bouin solution for 5 hours at $22^{\circ} \mathrm{C}$, and then dehydrated through an alcohol gradient consisting of 1 hours incubations in $25 \%, 50 \%$, $70 \%, 83 \%, 90 \%$, and $100 \%$ ethanol. The dehydrated tissue were cleared in xylene, infiltrated with melted paraffin for 2 hour at $65^{\circ} \mathrm{C}$, and embedded in paraffin blocks. Tissues were sectioned at $4 \mu \mathrm{m}$ thickness using rotary microtome (Leica), and the sections were placed on glass slides. Tissue sections were deparaffinized in xylene, rehydrated, and equilibrated in water. Antigen un-masking was performed by boiling sections in $10 \mathrm{mM}$ sodium citrate buffer for 10 minutes. Nonspecific binding was blocked using 3\% BSA in PBS for 30 minutes at $22^{\circ} \mathrm{C}$. samples were incubated overnight at $4^{\circ} \mathrm{C}$ with 1:200 dilutions of primary antibodies. Primary antibodies included the following: cytokeratin14 (ab7800), cytokeratin 18 (ab668) from Abcam (Cambridge, UK) and Prolactin (SC-7805) from Santa Cruz Biotechnology. after several washes, tissue sections 
were incubated with fluorescent-conjugated secondary antibody diluted 1:1000 in 1\% BSA in PBS for 1 hour at $22^{\circ} \mathrm{C}$. And then, slides were incubated with horse radish peroxidase-conjugated secondary antibody (1:500; Santa Cruz Biotechonolgy, Dallas, TX, USA) for 1 hour, at RT, following by incubation in 3, 3'-diaminobenzidin (Vector Laboratories, Burlingame, CA, USA). The slides were washed with PBS and then observed under a light microscope (Nikon, Tokyo, Japan).

\section{Results}

\section{CK14, CK18, and prolactin expression in bovine mammary gland and MAC-T cells}

In the heifer mammary gland, hematoxylin and eosin (H\&E)-stained sections revealed ducts penetrating and branching within the fibrous stroma, and there were fat pads in part of the tissue. CK18 expression was localized to the luminal compartment of the mammary ducts, whereas CK14 expression was detected in the basal/myoepithelial layer. Prolactin, which stimulates the mammary glands to produce milk, was detected in the epithelial duct of the bovine mammary gland (Fig. 1). In the mammalian mammary gland, most of the luminal epithelial cells express cytokeratin 18 (CK18) whereas the myoepithelial/basal cells express cytokeratin 14 (CK14). We therefore immunostained the MAC-T cells to analyze their CK18 and CK14 expression. Both CK18 and CK14 were strongly expressed in the DAPI-immunostained MAC-T cell line (Fig. 2).

\section{Transplantation of bovine MAC-T cells into mice dorsal tissue}

The exterior morphology of the mice dorsal area trans-

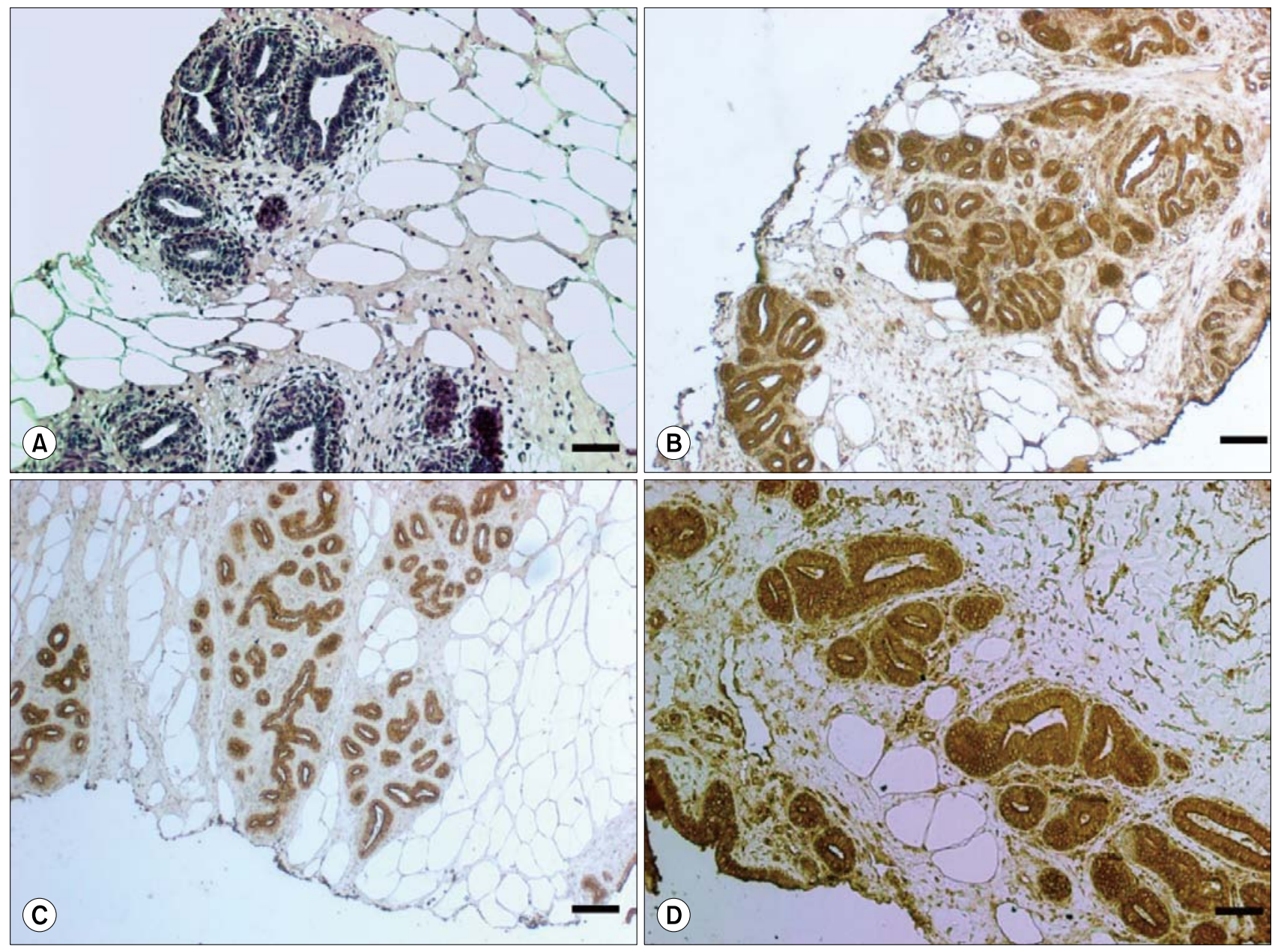

Fig. 1. CK14, CK18, and prolactin expression in bovine mammary gland. (A) Biopsied bovine mammary gland tissues stained with hematoxylin and eosin revealed a ductal structure. Immunostaining for CK14 (B), CK18 (C), and prolactin (D) showed strong positive expression of all three in the mammary gland duct. Bar $=50 \mu \mathrm{m}$ and $100 \mu \mathrm{m}$. 

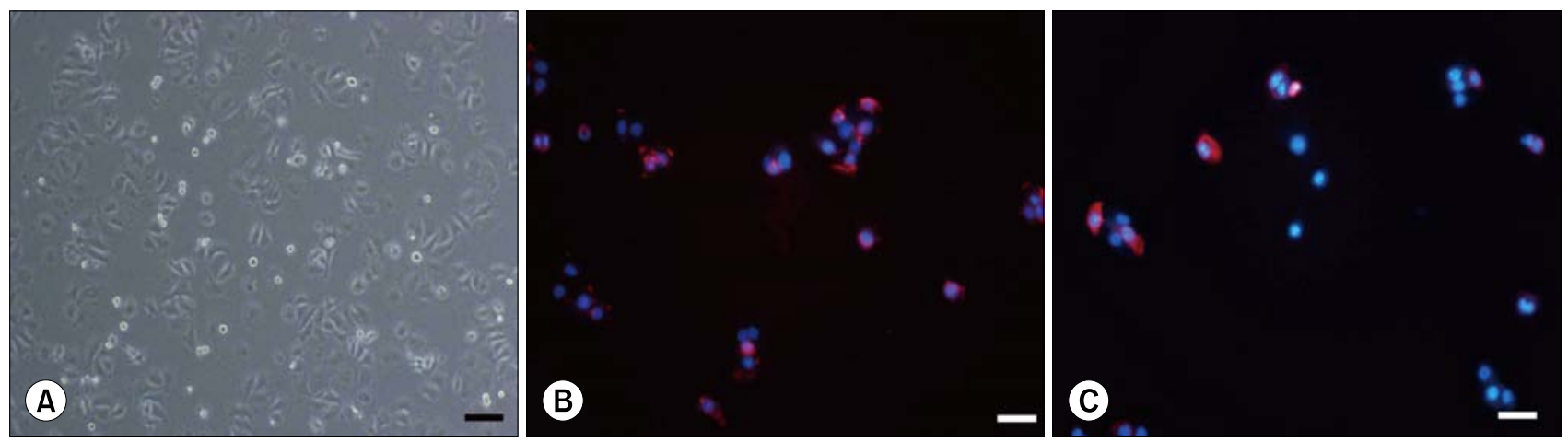

Fig. 2. CK14 and CK18 expression in MAC-T cells. (A) Image of MAC-T cell culture. Immunostaining for the basal cell marker CK14 (B) and the luminal cell marker CK18 $(\mathrm{C})$ showed strongly positive staining of both in bovine MAC-T cells. Bar=50 $\mu \mathrm{m}$
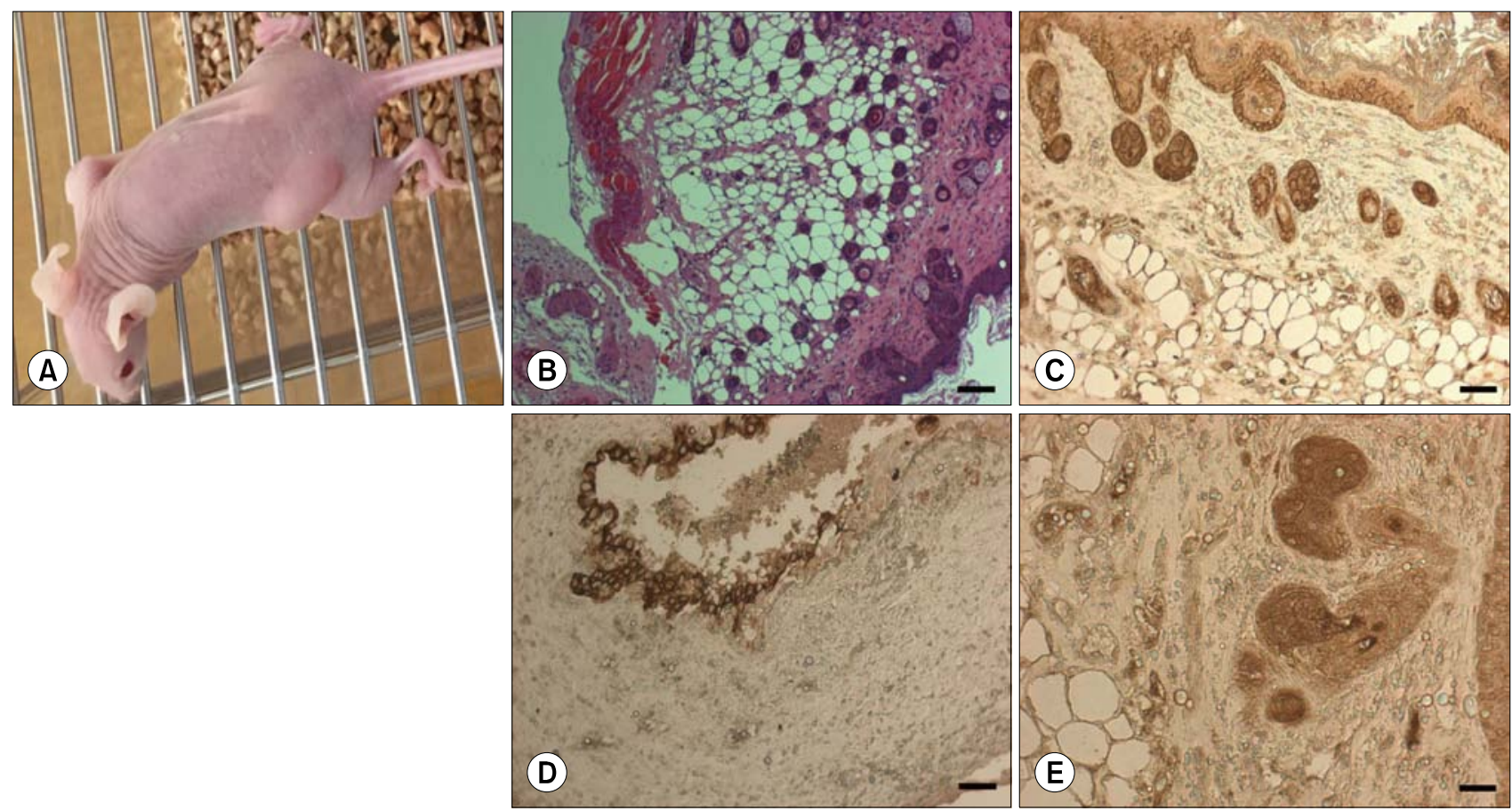

Fig. 3. CK14, CK18, and prolactin expression in MAC-T cell-transplanted mice tissue. (A) Images of MAC-T cell-transplanted mice tissue were taken after transplantation $(n=5)$. (B) Hematoxylin and eosin-stained section of the MAC-T cell-transplanted tissue at 6 weeks after transplantation. The basal cell marker CK14 (C) and the luminal cell marker CK18 (D) were localized exclusively in the duct-like structures of the dorsal tissue. (E) These ducts were strongly positive for prolactin upon immunostaining. Bar $=50 \mu \mathrm{m}$ in all figures.

planted with bovine MAC-T is shown in Fig. 3A. At 6 weeks after the cell transplantation, H\&E-stained sections of the MAC-T cell-transplanted dorsal tissue revealed the typical morphology of the tubuloalveolar female gland, with branching ducts that were surrounded by smooth muscle and small alveoli budding off the ducts. In addition, the organization and formation of the mammary duct revealed that it was surrounded by a fat pad. The duct-like structures resembled the bovine terminal ductal lobuloalveolar unit (Fig. 3B). We tested whether these ducts were formed by the CK14+ and CK18+ MAC-T cells. Immunostaining was used to detect the expression of CK14, CK18, and prolactin in the transplanted mouse tissue. The results showed strong CK14 and CK18 expression within the duct-like structures (Fig. 3B, C). In addition, prolactin was detected in the duct interior (Fig. 3E).

\section{Discussion}

Herein, we reported the first successful formation of bo- 
vine mammary alveolar duct-like structures in the dorsal tissue of mice at 6 weeks after MAC-T cell transplantation. Our results revealed significant ductal structure formation in the dorsal tissue, and similar expression of mammary gland epithelial markers (CK14 and CK18) and prolactin between the bovine mammary gland and the mouse dorsal tissue transplanted with MAC-T cells. In addition, histological analysis of the dorsal tissue revealed the typical morphology of the tubuloalveolar female gland.

It is well known that mammary gland cell types include an inner layer of $\mathrm{CK} 18+$ luminal cells and an outer layer of CK14+ myoepithelial cells. The luminal cells in the alveoli produce and secrete milk, whereas the myoepithelial cells generate a contractile force to eject the secreted milk during suckling by pups (11). For this reason, we provide immunostaining evidence that the transplanted MAC-T cells that had developed into mammary gland alveolar duct-like structures were $\mathrm{CK} 14+$ and $\mathrm{CK} 18+$ cells. Interestingly, PCR analysis did not show any prolactin expression in cultured MAC-T cells, but the hormone was strongly detected in the mouse-transplanted CK14+ and CK18 + MAC-T cells. Prolactin stimulates the mammary gland to produce milk and its level in females is increased during pregnancy. Otherwise, the physiological levels of prolactin in males serve to enhance luteinizing hormone receptors in Leydig cells, resulting in testosterone secretion (12). In our experimental design, the MAC-T cells were transplanted into male mice, not females. Nevertheless, our results showed the presence of prolactin from the transplanted MAC-T cells in the dorsal tissue.

Matrigel is commonly used for the preparation of human tumor xenografts in mice, tubule formation assays, and tissue morphogenesis by transplantation (13-15). In the present study, it was an important component for forming the bovine alveolar duct, where it acts as an extracellular matrix to aid formation of the mammary gland alveolus-like structure in the mouse dorsal tissue.

$\mathrm{BALB} / \mathrm{C}$ nude mice are defective in the natural killer cells of innate immunity as well as the $\mathrm{T}$ and $\mathrm{B}$ cells of humoral immunity. These mice are commonly used in research that requires the avoidance of xenograft rejection by $\mathrm{T}, \mathrm{B}$, and natural killer cells (16).

As a suggestion, MAC-T cell-transplanted female mice could be useful for further studies on the hormonal regulation of the bovine mammary gland and production of dairy protein. The female mammary gland is a dynamic organ that undergoes structural and functional changes in relation to growth, such as before and after puberty, and to reproduction events such as pregnancy and weaning (17). The process of initiation and branching morpho- genesis of mammalian gland is mutually regulated by hormone $(\mathrm{GH})$, estrogen, and insulin-like growth factor (IGF)-1 to generate a ductal tree (18). During lactation, various autocrine growth factors such as of TGF $\beta$, IGF-1, and IGFBP-5 are implicated in the regulation of milk secretion. In addition, vascular endothelial growth factor has been implicated in endothelial cell proliferation, angiogenesis, and vascular permeability. It may be essential for the establishment of the vascular network necessary to support milk secretion (19).

Certain aspects of this study remain unclear, such as how the bovine mammary gland ducts are formed in the mouse, and the difference between male and female hosts for transplantation. Nevertheless, this is the first study to have established a laboratory-scale model for developing bovine mammary alveolar duct in mouse dorsal tissue. These results suggest that duct-like tissue had been successfully formed at 6 weeks after transplantation of CK14 + and CK18 + MAC-T cells into mice dorsal tissue. This mouse model will be a useful tool for further research on the bovine mammary gland.

\section{Acknowledgments}

This work was carried out with the support of the Cooperative Research Program for Agriculture Science \& Technology Development (Project No. PJ010924), Rural Development Administration, Republic of Korea.

\section{Potential conflict of interest}

The authors have no conflicting financial interest.

\section{References}

1. Ryman VE, Packiriswamy N, Sordillo LM. Role of endothelial cells in bovine mammary gland health and disease. Anim Health Res Rev 2015;16:135-149

2. Hovey RC, Trott JF, Vonderhaar BK. Establishing a framework for the functional mammary gland: from endocrinology to morphology. J Mammary Gland Biol Neoplasia 2002;7:17-38

3. Parmar H, Cunha GR. Epithelial-stromal interactions in the mouse and human mammary gland in vivo. Endocr Relat Cancer 2004;11:437-458

4. Huynh HT, Robitaille G, Turner JD. Establishment of bovine mammary epithelial cells (MAC-T): an in vitro model for bovine lactation. Exp Cell Res 1991;197:191-199

5. Fekete ÁA, Givens DI, Lovegrove JA. Can milk proteins be a useful tool in the management of cardiometabolic health? An updated review of human intervention trials. Proc Nutr Soc 2016;75:328-341

6. Hill DR, Newburg DS. Clinical applications of bioactive milk components. Nutr Rev 2015;73:463-476 
7. Johnson TL, Tomanek L, Peterson DG. A proteomic analysis of the effect of growth hormone on mammary alveolar cell-T (MAC-T) cells in the presence of lactogenic hormones. Domest Anim Endocrinol 2013;44:26-35

8. Lee HY, Heo YT, Lee SE, Hwang KC, Lee HG, Choi SH, Kim NH. Short communication: retinoic acid plus prolactin to synergistically increase specific casein gene expression in MAC-T cells. J Dairy Sci 2013;96:3835-3839

9. McCoard SA, Hayashi AA, Sciascia Q, Rounce J, Sinclair B, McNabb WC, Roy NC. Mammary transcriptome analysis of lactating dairy cows following administration of bovine growth hormone. Animal 2016:1-10

10. Buser AC, Obr AE, Kabotyanski EB, Grimm SL, Rosen JM, Edwards DP. Progesterone receptor directly inhibits $\beta$-casein gene transcription in mammary epithelial cells through promoting promoter and enhancer repressive chromatin modifications. Mol Endocrinol 2011;25:955-968

11. Martignani E, Eirew P, Accornero P, Eaves CJ, Baratta M. Human milk protein production in xenografts of genetically engineered bovine mammary epithelial stem cells. PLoS One 2010;5:e13372

12. Hair WM, Gubbay O, Jabbour HN, Lincoln GA. Prolactin receptor expression in human testis and accessory tissues: localization and function. Mol Hum Reprod 2002;8:606-611

13. Yang J, Wang R, Li H, Lv Q, Meng W, Yang X. Lentivirus mediated RNA interference of EMMPRIN (CD147) gene inhibits the proliferation, matrigel invasion and tumor formation of breast cancer cells. Cancer Biomark 2016;17: 237-247

14. Dores C, Dobrinski I. De novo morphogenesis of testis tissue: an improved bioassay to investigate the role of VEGF165 during testis formation. Reproduction 2014;148:109-117

15. Zhang H, Eisenried A, Zimmermann W, Shively JE. Role of CEACAM1 and CEACAM20 in an in vitro model of prostate morphogenesis. PLoS One 2013;8:e53359

16. Shultz LD, Schweitzer PA, Christianson SW, Gott B, Schweitzer IB, Tennent B, McKenna S, Mobraaten L, Rajan TV, Greiner DL, et al. Multiple defects in innate and adaptive immunologic function in NOD/LtSz-scid mice. J Immunol 1995;154:180-191

17. Líška J, Brtko J, Dubovický M, Macejová D, Kissová V, Polák Š, Ujházy E. Relationship between histology, development and tumorigenesis of mammary gland in female rat. Exp Anim 2016;65:1-9

18. Howlin J, McBryan J, Martin F. Pubertal mammary gland development: insights from mouse models. J Mammary Gland Biol Neoplasia 2006;11:283-297

19. Hovey RC, Goldhar AS, Baffi J, Vonderhaar BK. Transcriptional regulation of vascular endothelial growth factor expression in epithelial and stromal cells during mouse mammary gland development. Mol Endocrinol 2001;15:819-831 